\title{
Study on the Rural Tourism Image of She Ethnic Group Based on Network Text Mining Analysis
}

\author{
WU Xinlei ${ }^{1,}{ }^{*}$, ZHANG Ying ${ }^{2}$ \\ ${ }^{1}$ Faculty of Business Administration, Heyuan Polytechnic, Heyuan, Guangdong, 517000, China \\ ${ }^{2}$ Faculty of Business Administration, Heyuan Polytechnic, Heyuan, Guangdong, 517000, China \\ *122088778@qq.com
}

\begin{abstract}
Network text mining analysis is an important method for the evaluation of tourism destination image,through the collection, screening and analysis of network data, the tourists perceptual information can be obtained,the attributes and characteristics of tourism destination image can be studied and judged.In this paper,ROST text analysis software has been used, Guangdong HuangLongyan She Ethnic Group Style Tourist Area has been taken as an Example,the tourists' after-sales feedback evaluation and travel notes from Tongcheng,com, Ctrip.com and other travel websites have been collected, high frequency characteristic words of tourism image have been dug and extracted, positive and negative effective factors of tourists' evaluation have been analyzed, it is found that She nationality brigade style, karst cave wonders and others are the most recognized image perception by tourists; but the problem of negative evaluation on the charge of entrance tickets and parking,temples and others is also very prominent.Therefore, the tourist area needs to change the operation mode of the single ticket economy,by increasing supply projects of diversity of scenic spots,transforming rural experience tourism facilities and inheriting and cultivating the unique culture of the minority nationality, so that the innovation and development of tourism industry in Guangdong Zhang Xi She Nationality Area and regional rural can be promote.
\end{abstract}

\section{Keywords: Network Text;ROST; She Ethnic Group; Rural Tourism}

\section{Introduction}

The popularity and the rapid development of the Internet technology makes tourism have closer link with the Internet. Tourists' travel and Internet ticket reservation have become the mainstream, which present real-time, intuitive after-sales evaluation on scenic spots. Therefore, focusing on tourism evaluation text on the Internet, collecting and exploring tourists' perception information will become the important means to study the tourism destination image. Chinese scholars such as Yang Xueke conducted the analysis of the projected image of Zhangjiajie tourism destination based on network text[1]. Duan Shengkui collected the network evaluation text collection of couch surfering visitors, and explored their emotional engagement and experience perception[2]. Yin Xiaona took three lanes and seven alleys in Fuzhou as example to make the targeted research on visitors' cultural awareness and tourism image. With the implementation of the "universe travel" , rural tourism reform and tourism image brand shaping has become the core for the transformation development of traditional rural tourism destination. Therefore, by using the Internet text data, the analysis of the rural tourism scenic tourists' perceptual experience of travel model, local conditions and customs, scenic spot' characteristics, charging status, service attitude, etc., will help the rural tourism destination to clearly understand its superiority in the minds of tourists, so as to provide important basis for the transformation development of the scenic spot[3].

\section{Overview of Research Area}

She Ethnic Township of Zhangxi in Guangdong is located in the northeast of Dongyuan County, on Shangguan town in the east, Zengtian town and Luohu town in the south, Suntian town in the west, and Chuantang town in the north town. She Ethnic Township of Zhangxi has 19158 people in total, and is a major settlement for She minority in Dongyuan county, with the population of She minority 
of about 6000 people. Among the population of She minority in Guangdong province, $50 \%$ of the minority population is in Heyuan city, in which She Ethnic Township of Zhangxi accounts for 23\%. So, Zhangxi has the title of the living center of She minority in Guangdong. The characteristic custom "Blue General" tour held by She Ethnic Township of Zhangxi on April 9th in lunar calendar is the intangible cultural heritage project in Heyuan city. Guangdong Huanglongyan She minority scenic spot is located in Gaozhang Mountains, She Ethic Town, Zhangxi, Zhangyuan County, $59 \mathrm{~km}$ from Heyuan city, and covers an area of about 20 square kilometers. On January 26, 2003, the scenic spot strived to get 500000 yuan of Guangdong tourism poverty alleviation fund, and then it was open after the preparation. After years' investment and operation, now, the scenic spot is the only one with She minority customs as the theme in Guangdong province, including colorful karat cave tour, She minority custom tour and mountain ecological tour. In the scenic spot, there is Gaozhang Mountain, lion-type reservoirs and seven karst caves such as Huanglongyan, Ceshen cave, Yan rock and so on. It also has the exhibition hall of She minority totem, the performance of She minority custom, jungle water float. All of these are the important places to experience the unique natural landscape of She ethic township of Zhangxi and appreciate the She minority customs culture. The sustainable development of scenic spot effectively drives the local development of the third industry, such as catering, transport, tourism product, with the positive rural tourism poverty alleviation effect[4]. With the statistics of tourism population and income in 2015 as an example, the scenic spot received a total of 136000 tourists in total, and the business income was 3.012 million yuan, with the tax of 185000 RMB.

\section{Research Method}

Tourism image is the external characterization of tourist attractions, travel service, social environment, natural environment, etc. with the features of comprehensiveness, stability and plasticity. It is the integration of tourist's experience perception and emotional evaluation of all the elements of the tourism destination[5]. The measurement for rural tourism scenic spot image involves many factors, with more complex situation. The traditional structural questionnaire survey and measurement is often limited by the respondents' personal subjective choice and hobby. It is difficult to conduct a comprehensive analysis and evaluation on the rural tourism image. In terms of the data mining means of the unstructured measurement of tourism image, ROST Content Mining is a content mining system software developed by professor Shenyang from the school of information management at Wuhan university; he carried the targeted analysis of rural tourism network text, including word segmentation, word frequency statistics, emotional tendency, semantic network and social network, etc., so as to realize the organic combination of qualitative and quantitative analysis, to make the evaluation of the tourism destination image more reliable[6].

This paper aims to use ROST text analysis software to collect the tourists' objective after-sales comments, travel notes on Guangdong Huanglongyan She minority scenic spot from the tourism websites such as ctrip, Tongcheng, etc., to explore and extract the feature words with high frequency on tourism image, so as to study the tourism image of the scenic spot such as the unique culture, the classical and traditional production and living utensils and colorful She minority performance of song and dance, the peasant catering with unique flavor, with the hope of providing reference for the tourism brand building.

\section{Research Process}

\subsection{Cognitive Analysis of Scenic Image Based on ROST Content Mining}

With the investigation of the tourism websites that sell the ticket of Guangdong Huanglongyan She minority scenic spot, the after-sales comments of tourists were collected from the websites, such as Tongcheng, Ctrip, Lantu, 88gogo, Baidu travel, Mafengwo, Meituan, Lvmama, etc., and there were 242 texts in total (seen in table 1), in which the sample quantity of Ctrip is the main part, with the number of 136. 
Table 1 statistics of the network text of Huanglongyan She minority scenic spot

\begin{tabular}{cccc}
\hline Network name & Sample quantity & Network name & Sample quantity \\
\hline Tongcheng & 136 & Lantu & 10 \\
88 gogo & 15 & Baidu travel & 8 \\
Mafengwo & 14 & Meituan & 21 \\
Lvmama & 12 & Ctrip & 26 \\
\hline
\end{tabular}

The 242 texts were filed with the name of "after-sales evaluation of Huanglongya.txt", and it was analyzed by ROST software. Through extracting words with high frequency and removing words without meaning, 40 words with effectively high frequency were concluded, such as "karat cave", "She minority", etc. Meanwhile, with the key word searching by ROST software on Baidu.com and Youdao.com to find the text of Huanglongyan's official propaganda and news report, it was found that there were 29400 texts on Baidu.com and 26600 texts on Youdao.com. With the analysis of the word frequency from the effective texts, it was found that there were 19 feature words of network propaganda, such as "She minority", "custom", etc.

Table 2 the feature words with high frequency in tourists' comment, network propaganda of Huanglongyan She minority scenic spot

\begin{tabular}{|c|c|c|c|c|c|c|c|c|}
\hline $\begin{array}{c}\text { Orde } \\
\mathrm{r}\end{array}$ & $\begin{array}{l}\text { Feature } \\
\text { word of } \\
\text { tourist } \\
\text { comment }\end{array}$ & $\begin{array}{l}\text { Frequ } \\
\text { ency }\end{array}$ & $\begin{array}{l}\text { Orde } \\
\mathrm{r}\end{array}$ & $\begin{array}{l}\text { Feature } \\
\text { word of } \\
\text { tourist } \\
\text { comment }\end{array}$ & $\begin{array}{l}\text { Frequ } \\
\text { ency }\end{array}$ & $\begin{array}{c}\text { Orde } \\
r\end{array}$ & $\begin{array}{c}\text { Feature word } \\
\text { of tourist } \\
\text { comment }\end{array}$ & $\begin{array}{c}\text { Freque } \\
\text { ncy }\end{array}$ \\
\hline 1 & Karst cave & 61 & 20 & $\begin{array}{c}\text { Environmen } \\
\mathrm{t}\end{array}$ & 9 & 1 & She minority & 274 \\
\hline 2 & $\begin{array}{l}\text { She } \\
\text { Minority }\end{array}$ & 40 & 21 & Interesting & 9 & 2 & Custom & 211 \\
\hline 3 & Scenic spot & 34 & 22 & Free & 9 & 3 & Ticket & 33 \\
\hline 4 & Feeling & 24 & 23 & Tour guide & 8 & 4 & Hot spring & 28 \\
\hline 5 & Charge & 24 & 24 & Good & 8 & 5 & Scenic spot & 25 \\
\hline 6 & Grotto & 22 & 25 & Introduction & 8 & 6 & drift & 22 \\
\hline 7 & Ticket & 22 & 26 & Rock & 7 & 7 & Preferential & 19 \\
\hline 8 & Worthy & 15 & 27 & $\begin{array}{c}\text { Entrance to a } \\
\text { cave }\end{array}$ & 7 & 8 & karst cave & 16 \\
\hline 9 & Custom & 14 & 30 & $\begin{array}{c}\text { Thurificatio } \\
n\end{array}$ & 7 & 9 & $\begin{array}{l}\text { Chinese } \\
\text { chestnut }\end{array}$ & 11 \\
\hline 10 & Scenery & 14 & 31 & Parking fee & 7 & 10 & Characteristic & 10 \\
\hline 11 & $\mathrm{Ok}$ & 13 & 32 & Beautiful & 6 & 11 & Dragon palace & 10 \\
\hline 12 & $\begin{array}{l}\text { Characteris } \\
\text { tic }\end{array}$ & 12 & 33 & $\begin{array}{l}\text { Mountain } \\
\text { villa }\end{array}$ & 6 & 12 & Culture & 9 \\
\hline 13 & Hot spring & 12 & 34 & $\begin{array}{l}\text { Performance } \\
\text { of song and } \\
\text { dance }\end{array}$ & 6 & 13 & Only one & 9 \\
\hline 14 & Satisfied & 12 & 35 & $\begin{array}{c}\text { Worthy } \\
\text { sightseeing }\end{array}$ & 6 & 14 & Resort & 9 \\
\hline 15 & Monk & 11 & 36 & stalactite & 6 & 15 & the hakkas & 8 \\
\hline 16 & $\begin{array}{c}\text { go } \\
\text { downhill }\end{array}$ & 11 & 37 & Cheating & 6 & 16 & Recommend & 7 \\
\hline 17 & Culture & 10 & 38 & Air & 5 & 17 & Fun in wild & 6 \\
\hline
\end{tabular}




\begin{tabular}{lccccc|ccc}
18 & Very good & 10 & 39 & Unique & 5 & 18 & Mountain villa & 6 \\
19 & Special & 9 & 40 & Minority & 4 & 19 & Peasant family & 5 \\
\hline
\end{tabular}

\subsection{Emotional Analysis of Huanglongyan She Minority Scenic Spot}

The emotional attitude in network text mainly target the analysis of noun and adjective of visitors' comments with emotional color from the text data, so as to obtain the tourists' perception experience and intuitive impression on the scenic spots, destination[7]. By using the ROST, the emotional analysis is conducted for the network text of Guangdong Huanglongyan She minority scenic spot, from which we can see that the visitors have higher positive attitude and recognition to it. The tourists with positive emotion accounts for 57.2\%, mainly reflected in "worthy sightseeing", "good", "satisfied", "unique" and so on. But there is $30 \%$ of the negative emotion, especially the problems of "cheating", "parking fee", "sub-project charge", "traffic", etc., are serious (seen in table 3).

Table 3 perceptual and emotional analysis of tourism image of Huanglongyan She minority scenic spot

\begin{tabular}{|c|c|c|c|c|c|}
\hline $\begin{array}{l}\text { Emotion } \\
\text { category }\end{array}$ & Term quantity & Proportion & Degree & Term quantity & Proportion \\
\hline \multirow{3}{*}{$\begin{array}{l}\text { Positive } \\
\text { emotion }\end{array}$} & \multirow{3}{*}{151} & \multirow{3}{*}{$57.2 \%$} & General & 7 & $4.6 \%$ \\
\hline & & & Moderate & 29 & $19.2 \%$ \\
\hline & & & High & 115 & $76.2 \%$ \\
\hline $\begin{array}{l}\text { Neutral } \\
\text { emotion }\end{array}$ & 55 & $20.8 \%$ & & & \\
\hline \multirow{3}{*}{$\begin{array}{l}\text { Negative } \\
\text { emotion }\end{array}$} & \multirow{3}{*}{58} & \multirow{3}{*}{$30.0 \%$} & Generate & 12 & $20.7 \%$ \\
\hline & & & Moderate & 22 & $38.0 \%$ \\
\hline & & & high & 24 & $41.3 \%$ \\
\hline Total & 264 & 100 & & & \\
\hline
\end{tabular}

\section{Result Analysis}

Huanglongyan She minority scenic spot as the representative of the scenic spots with She minority customs as the theme. The official propaganda takes She minority customs, karst cave landscape and characteristic Chinese chestnut festival, dragon temple legend, the hakka culture, the farmhouse with fun in the wild, etc. as the main brand image shaping target. According to the analysis of the after-sales comments and travel notes on the major websites, we can know that visitors have the good comprehensive impression on Huanglongyan. From table 2, we can see that the word with the highest frequency is "cave", and the word with higher frequency is "She minority", which illustrates the Huanglongyan resources has gained the recognition of the tourists. These words such as "Worthy" and "Ok", "Interesting", "Characteristic" appear with high frequency, ranking the top. It can be seen that in the process of tour, tourists have deep impression on specialty of cave, She minority performance, etc.

In table 3, we can see the proportion of positive emotion of tourists is $57.2 \%$, neutral emotion is $20.8 \%$, and negative emotion is $30.0 \%$. This proportion rate shows that visitors mainly have positive emotion on Huanglongyan, but the proportion of negative emotion is higher, which should be noticed by the operator of the scenic spot. In the positive emotion of visitors, we can see the highly positive emotion accounts for $76.2 \%$, moderate positive emotion accounts for $19.2 \%$, while generally positive emotion accounts for $4.6 \%$. So, among the visitors with positive comment, their preference of Huanglongyan She minority scenic spot is very high.

When collecting comments in the websites, it is found that the scenic spot has no sales cooperation with many websites, and the text in news and propaganda links basically takes the cooperative extension of the surrounding hot spring tour as a priority. There is less event marketing, and 
propaganda theme activities. In the websites of searching the eight major ticket sales or group purchase, only Tongcheng has more comments. And there are a fewer comment samples in other websites. This reflects the popularity of Huanglongyan in other areas is lower, and its publicity should be enhanced, with the expansion of the cooperation with the Internet enterprises. In addition, it is possible to build the scenic spot's member point experience, to let visitors take part in the interaction with the scenic image shaping, so as to form good social reputation. In table 2, we can see a negative words, such as "fee", "cheating" and "parking" with higher frequency; therefore, the ticket price of the scenic spot can be adjusted, and the components and parking charge system should be standardized; through the network to make an appointment, member point, group reservation, etc. it can give discount to tourists so as to improve the negative emotional factors.

\section{Conclusion}

ROST text analysis software is used to deeply analyze feature words with high frequency with the data sources of after-sales comment and travel notes on Guangdong Huanglongyan She minority scenic spot. Overall, ethnic customs and cave environment are the key words of the positive comments, which show that Huanglongyan scenic spot is a cultural carrier and the tourism area with distinctive image of natural scenery. the According to the network propaganda rating statistics, the overall popularity of Huanglongyan scenic spot is not high, without enough publicity. Huanglongyan scenic spot should take karst cave and She minority as the main body, to carry out the positive publicity so as to expand popularity of the scenic spot. The price for the temples and special performance, etc. in the scenic spot is high, which is a major content of tourists' negative evaluation. The control of the ticket price point with scenic spot service and special tourism goods as the main content can make up and improve the negative affection of tourists. Therefore, Huanglongyan She minority scenic spot should do well in the illustration service, guide services; combined with the construction of She minority cultural center and museum construction in the scenic spot, and through online and offline promotion activities, it should plan to set up the experience projects with the outstanding theme of "traveling characteristic karat cave and appreciating She minority customs" and vivid brand, so as to make more people know the scenic spot, recommend the scenic spot, and actively play the tourism poverty alleviation comprehensive effect on She ethnic township of Zhangxi in Guangdong.

\section{Acknowledgement}

The author would like to thank support of Heyuan Polytechnic training package development project (No.:Hzy2016ybpxb05), Scientific research project of Heyuan Polytechnic (No. : 2014-KJ06).

\section{References}

[1]Yang Xueke, Wu Jianqing, Zhang Xiaohong and so on.Graduate Journal of Zhongshan University (natural science. Medical section), 2014, p.82, in Chinese

[2]Duan Shengkui, Zhang Shulin, Jiang Liao.Travel Journal, 2013, p.101, in Chinese

[3]Fu Yeqin, Wang Jianxin, Zheng Xiangmin .Travel forum, 2013, p.59, in Chinese

[4]Chen Ming.Guangdong technical normal college journal, 2008, p.2, in Chinese

[5]Li Xi, Ye Sheng, Wang Dong.Travel journal, 2011, p.57, in Chinese

[6]Cai Yi, Yang Yang, Yin Hongmei.Journal of Chongqing Normal Univeristy (natural science), 2015, p.126, in Chinese

[7]Yin Xiaona, Zheng Xiangmin. Journal of Beijing international studies university, 2015, p.62, in Chinese 